\title{
Open Government Data Use by the Public Sector - an Overview of its Benefits, Barriers, Drivers, and Enablers
}

\author{
Ilka Kawashita \\ University of Phoenix \\ ikawashi@gmail.com
}

\author{
Ana Alice Baptista \\ Algoritmi Center, Minho University \\ analice@dsi.uminho.pt
}

\author{
Delfina Soares \\ United Nations University \\ soares@,unu.edu
}

\begin{abstract}
Although governments publish large amounts of open data, their use by the public sector is still in its infancy. Therefore, this study aims to gain insights into promoted benefits and factors that hinder (barriers), facilitate (enablers), and propel (drivers) Open Government Data (OGD) use and reuse by the public sector. A systematic literature review of 38 publications resulted in an overview of these factors. Findings suggest that OGD use benefits are increased transparency and the development of new/improved processes, products, and services. Moreover, open data institutionalization and pressure from external stakeholders drive the use. However, data issues and the lack of supporting open data organizational structure, capacity, and skills hinder OGD use. While the existence of open data policy and laws, motivated leadership, and open data infrastructure enable it. Thus, if OGD use is to reach maturity, administrations need to create the means to institutionalize open data.
\end{abstract}

\section{Introduction}

Governments rely on Information and Communication Technologies (ICT) to support operations and drive their digital transformation. Open Government Data (OGD) is at the heart of this revolution. OGD is open data produced with public money that anyone can freely access, use, modify and share for any purpose [1]. Governments produce large amounts of data. They have created data portals to make data more accessible and usable by the public [2]. Notwithstanding, little is known about the use and reuse of these data within public administrations [3], [4], [5], as few studies addressed the topic from the public sector perspective, and reviews of the literature are lacking. Thus, a review of the benefits promoted and the factors that hinder (barriers), facilitate (enablers), and propel (drivers) OGD use from the Administration perspective can broaden our knowledge and understanding.

The benefits associated with Open Government Data (OGD) is a recurring topic in the literature [6], [1],
[7], [8]. OGD has been claimed to increase transparency and accountability [9], [1], [10], [11], [12] to promote the development of improved public policies [1], [7], [13], [8], [14], [10], foster the offer of new processes, products, and services [1], [10], [13], [11], and increase civic participation and public engagement [9], [11], [8], [13]. However, to harness its value and heap potential benefits, data should be used [11].

Despite OGD's potential transformative value [15], evidence of such transformation is scarce, as several barriers hinder or impede use. Some examples are unfavorable organizational culture towards open data [16], [17], [5], [18], users do not possess technical skills and training [2], high cost of hiring skilled people to use open data [19], [20], [13], [21], [16], [5], and difficulty to interact with data provider [1], [19], [22], [23].

Thus, to remove and ease barriers, researchers investigated and proposed enablers [4], [11], [12], and drivers [17], [21], [24]. External factors, such as pressure from international organizations to use OGD [21] and the existence of public open data policy, laws, and standards [24], [20], [25] compel administrations to use OGD. Others, such as favorable open data culture [4], [20], enable users to overcome corresponding barriers.

In this context, this systematic literature review aims to report an overview of the benefits, barriers, drivers, and enablers (BBDE) of Open Government Data (OGD) use by the public sector. We argue that this review will provide some factors that are specific to the public sphere. Hence, practitioners, public managers, and decision-makers can use these factors to change and improve open data use processes, policies, and strategies to overcome barriers and adopt facilitating measures to promote OGD use to realize positive benefits. This review resulted in the identification of BBDE themselves. We contribute to the Digital Government research domain and the Public Administration and data science fields by synthesizing these factors in the public sector, offering insights into new research venues.

The remainder of this paper is organized as follows. Section 2 provides a background for this study. Section 
3 presents our research approach and method used to conduct this literature review. Section 4 documents the review. Section 5 presents our findings and discussion. Finally, in Section 6, conclusions, future research, and study limitations are discussed.

\section{Background}

Many studies examined OGD from multiple perspectives and varying factors. For example, in a seminal publication, Janssen and colleagues [1] explored the benefits, adoption barriers, and myths of Open Data and Open Government, some of which refer to OGD use.

With a broad perspective, Luna-Reyes [22] assessed OGD policy progress in the United States (US) Federal Government. The author identified enablers and current challenges, also providing recommendations to move OGD's vision forward. Parker and colleagues [14] identified three patterns of OGD use for better delivery of public services.

Focusing on OGD local and national communities perspectives, Chorley [21] explored the OGD challenges to records management within the public sector in England. In contrast, Kim and Eom [17] analyzed managerial factors as drivers and challenges of open data in Korea. Moreover, Susha and associates [26] investigated which organizational measures could facilitate OGD use in the Netherlands and Sweden.

Several studies explored the perspectives of intermediaries, developers, actors, communities, and stakeholders of the Open Government Data (OGD) ecosystem. Kucera (2017) [19] identified barriers to publishing and using OGD faced by stakeholders in the Open Data ecosystem. Some authors focused on a specific community. Martin [15] explored OGD implementation and use barriers in the perception of United Kingdom (UK) OGD community members. Mockus [27] identified the legal barriers OGD mashup developers face in EU member countries. Moreover, Shepherd and colleagues (2019) [16] identified technical and organizational barriers to OGD use in the perspectives of open government and information practitioners in England.

With the focus in Brazil and Latin America, Albano and colleagues explored OGD projects' benefits, motivational factors, facilitators, and barriers from public project managers' [9], and users' [11], intermediaries working with budget data in Brazil [10] and four Latin-American countries [13]. They also examined these factors from the perspective of Brazilian OGD ecosystem actors [12].

From a process perspective, Mockus [28] conducted an empirical study to identify the impediments users faced using OGD in a data science project.

Saxena focused on the perspectives of developing countries. The author investigated the significance, drivers, and barriers to ensure the use and reuse of OGD in Sri Lanka [29], Oman [30], and the Philippines [31]. Moreover, Shao and Saxena [32] identified organizational, social, legal, and technical barriers toward instituting a robust OGD initiative in Tanzania.

From a project's perspective, Cahlikova \& Mabillard [20] identified the challenges to introducing the Open Government Data project in Switzerland. In contrast, Melin [33] investigated the myths, challenges, and benefits of developing an OGD platform at a Swedish local government. Ma and Lam [23] identified 43 barriers faced by stakeholders in an open data project in Hong Kong. They investigated barriers interdependencies using social network analysis (SNA).

From an OGD-driven applications perspective, Cranefield and colleagues [34] explored the benefits, barriers, and enablers in the view of Open Government Data (OGD) apps developers in New Zealand. In contrast, Wieczorkowski [5] identified barriers to the implementation of OGD-based solutions with a focus on the maturity of data formats, automated processing with Application Programming Interface (API), and the concept of Linked Open Data (LOD).

In the niche of studies adopting novel approaches, Gebre \& Morales [35] investigated the nature of context-related information provided with the datasets from Canada, the United Kingdom (UK), and the United States (US) and identified the challenges users reported. In contrast, Cho \& Lee [25] examined the factors driving the use of OGD from data providers' perspectives in the public sector to improve data publication. Smith and Sandberg [18] explored how innovation barriers affect OGD use in different ITIL service life cycle phases. The authors also examined how the perceptions of the barriers vary across different types of OGD in the Swedish public transport sector.

Recurrent literature reviews bring the body of knowledge together. They are needed in general and specific levels (use or publication); thus, authors can provide insights, research paths and tackle research barriers [3]. Therefore, this review investigates the focus of OGD use benefits, barriers, drivers, and enablers reported in previous studies and reviews ([6], [3], [24], [4], [36]). Attard and colleagues [6] assessed different aspects of OGD initiatives, including OGD publishing and consumption enablers, barriers, and their impact on OGD life cycle processes. The historical development, barrier types, and different OGD research foci were presented by Crusoe \& Melin [3]. Huang and associates [24] identified and qualified barriers that hinder Open Government Data (OGD) in China. Khurshid and 
colleagues [4] explored established theories and determinants of OGD adoption in the public sector. Finally, Roa and colleagues [36] surveyed the impact and occurrence of different problems before, during, and after an open government data initiative using the Information Systems (IS) adoption process.

In summary, current research focuses on factors that hinder, facilitate, or drive OGD use (consumption) in specific communities, society, citizens, and the private sector. The public sector perspective is unclear, and research does not support informed decisionmaking about OGD use (consumption) in the public sector. In this context, a better understanding of these factors is needed. However, reviews addressing these topics are lacking.

\section{Research Approach}

Webster \& Watson [37] consider reviews of existing literature crucial for academic research. It uses Kitchenham's [38] systematic literature review method, as shown in Figure 1. The three main steps are planning, conducting, and reporting the review.

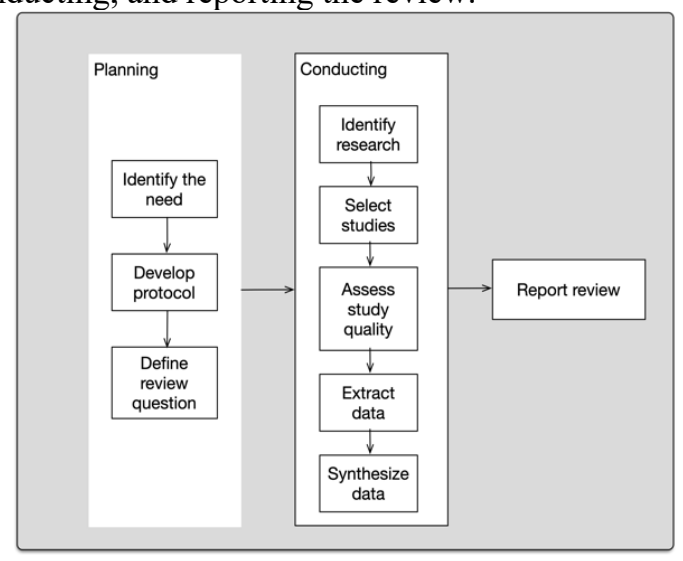

\section{Figure 1 - Systematic literature review (adapted from Kitchenham [38])}

Selected papers were analyzed according to the following strategy. First, one researcher read papers to identify benefits, barriers, drivers, and enablers (BBDE) categories. For example, Janssen and colleagues [1] categorized barriers at the institutional level, the task complexity of handling the data, the use of open data and participation in the open-data process, legislation, information quality, and technical level. Zuiderwijk and associates [7] categorized benefits into political and societal, economic, and technical, and operational. Next, papers were scrutinized for BBDE, and each identified factor was placed into a category. Then, similar factors were grouped into a normalized label. An example of such a label is the technical and operational benefit
"Improved data management," which groups the benefit discussed in four papers [1], [7], [13], [10]. Finally, factors not related to OGD use in the public sector were removed. All nuances of the phenomenon during initial coding [39] might not be captured, as it was done by one researcher. Thus, two other researchers reviewed categorization to reduce the bias introduced by data collection and initial coding.

This review outcomes are four lists with factors reported in the literature - one list for each factor. Factors are grouped into categories.

The following section describes how this review was conducted according to the method discussed above.

\section{Literature review}

This review intends to answer the following research questions from the public sector perspective: RQ1 - What are the benefits promoted by OGD use? RQ2 - What are the factors that hinder (barriers) OGD use? RQ3 - What are the factors that facilitate or enable (enablers) OGD use? RQ4 - What are the factors that propel (drivers) OGD use?

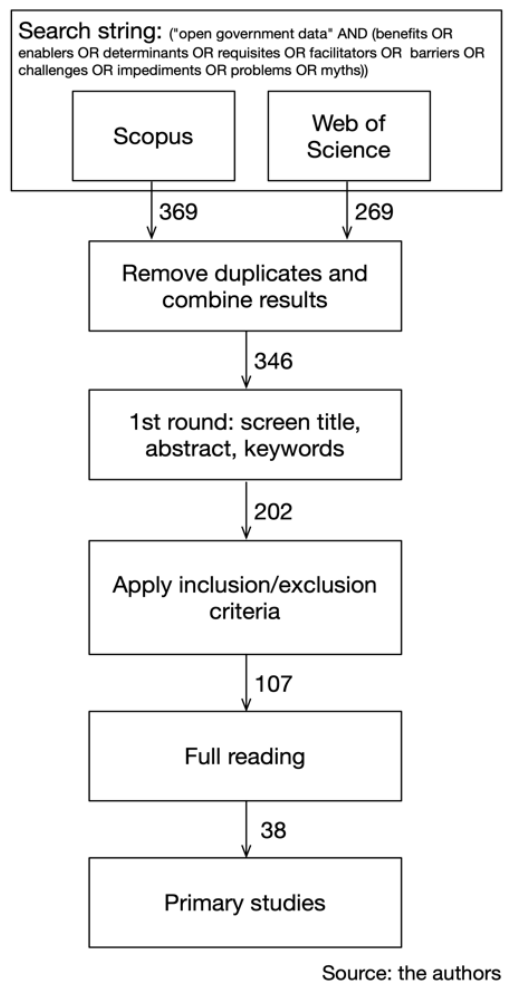

Figure 2 - Search and select protocol

Figure 2 presents this review's search and selection strategy and its results. First, a manual search was 
conducted on Scopus and Web of Science (WoS). These databases provide appropriate coverage of Social Science journals [40] and studies related to Digital Government, Public Administration, and Open Government Data. Searches were conducted in January 2021. For retrieving records, search fields were title, abstract, and author keywords on Scopus, adding keywords plus ${ }^{\circledR}$ on WoS. We focused on journal papers, conference proceedings, and book chapters. The search start date was the default of each database: 1960 (Scopus) and 1900 (WoS). Citations of identified publications were examined to find additional relevant literature and augment the review basket [37]. Studies cited in several selected articles such as [1] and [6], which contained words in the search string, were added to the basket and perused.

Inclusion criteria applied to select publications: empirical studies and literature reviews related to OGD use benefits, barriers, problems, challenges, enablers, determinants, or drivers; and focus on the public sector. Exclusion criteria: OGD used by the private or third sectors; not written in English, Portuguese, or Spanish; inaccessible.

Some studies [4], [1], [41] did not address specific OGD use benefits, barriers, drivers, and enablers (BBDE). Nevertheless, they were included and used to seed initial coding because they examined BBDE from the public sector perspective.

The search did not produce results before 2012 . Thus, the resulting studies were published between 2012 and 2020. As shown in Figure 2, 38 publications were selected as primary studies. Five are literature reviews, and the remaining 33 are empirical studies. Papers were published in peer-reviewed journals and conferences. In addition, books, chapters, tutorials, guidelines, reports, and official documents produced by governments and reputable international organizations, such as the European Union and United Nations, were included as supplementary sources. They were found following the citation trees of selected studies and retained when relevant. They aid in reducing bias, provide guidance to interpret findings, recommend research venues, and determine our inferences' strength.

The next section presents the results of our analysis and synthesis and our findings and discussion.

\section{OGD use benefits, barriers, drivers, and enablers}

Some researchers [1], [3], [6], [36], [41], [42] examined the open data field from a variety of perspectives, such as economic, social, technical, institutional, operational, political, and legal. Hence, this study adopts and adapts the perspectives found in the literature to categorize benefits, barriers, drivers, and enablers (BBDE). Table 1 presents these categories and provides examples to illustrate them.

Table 1- BBDE categories

\begin{tabular}{|c|c|}
\hline Category & Description \\
\hline $\begin{array}{l}\text { Political and } \\
\text { social }\end{array}$ & $\begin{array}{l}\text { Includes, for example, political and } \\
\text { social benefits such as increased } \\
\text { transparency and civic participation. }\end{array}$ \\
\hline $\begin{array}{l}\text { Policy and } \\
\text { legal }\end{array}$ & $\begin{array}{l}\text { Relates to the existence or lack of open } \\
\text { data policies, laws, regulations, } \\
\text { standards, which impact OGD use. For } \\
\text { example, data published under } \\
\text { copyright license or with use } \\
\text { restrictions cannot be redistributed or } \\
\text { reused. }\end{array}$ \\
\hline Cultural & $\begin{array}{l}\text { Perceptions and beliefs change the way } \\
\text { countries and organizations define } \\
\text { openness. For example, some public } \\
\text { institutions are more secretive and } \\
\text { closed than others and may perceive } \\
\text { data published by other agencies as } \\
\text { untrustworthy and not use it. Thus, } \\
\text { cultural aspects influence OGD use. }\end{array}$ \\
\hline $\begin{array}{l}\text { Economic and } \\
\text { financial }\end{array}$ & $\begin{array}{l}\text { There is a cost to produce, publish, and } \\
\text { maintain open data. Thus, money is } \\
\text { needed to ensure the sustainability of } \\
\text { OGD-driven initiatives. However, } \\
\text { there should be no cost (or a marginal } \\
\text { cost) for data consumers. No standard } \\
\text { cost model is available for data } \\
\text { obtained from intermediaries. An } \\
\text { economic OGD use benefit is the } \\
\text { creation of new/improved public } \\
\text { services and products. }\end{array}$ \\
\hline $\begin{array}{l}\text { Organizational } \\
\text { and } \\
\text { institutional }\end{array}$ & $\begin{array}{l}\text { The use of open data requires the use } \\
\text { of new and not well-established } \\
\text { technologies. So, institutions need to } \\
\text { create appropriate organizational } \\
\text { structures, capabilities, routines, and } \\
\text { processes to use it. }\end{array}$ \\
\hline $\begin{array}{l}\text { Operational } \\
\text { and } \\
\text { technical }\end{array}$ & $\begin{array}{l}\text { Technical aspects concern the nature of } \\
\text { the data itself. For example, low data } \\
\text { quality (incomplete, outdated), lack of } \\
\text { metadata, and dataset publication } \\
\text { format (pdf, xls) could hinder data use. } \\
\text { Finally, operational aspects encompass } \\
\text { infrastructure and processing capacity } \\
\text { to use open data. }\end{array}$ \\
\hline
\end{tabular}

Table 2 presents the selected publications and summarizes how studies contributed to Open Government Data use barriers, benefits, drivers, and enablers tables presented below. 
Table 2 - Selected studies

\begin{tabular}{|c|c|}
\hline $\begin{array}{l}\text { Publication } \\
\text { type }\end{array}$ & Publication reference \\
\hline $\begin{array}{l}\text { Literature } \\
\text { reviews }\end{array}$ & {$[6],[3],[24],[4],[36]$} \\
\hline $\begin{array}{l}\text { Conference } \\
\text { and journal } \\
\text { articles }\end{array}$ & $\begin{array}{l}{[15],[10],[1],[12],[43],[44],[13],[19],} \\
{[5],[35],[29],[31],[34],[27],[16],[30],} \\
{[7],[8],[21],[11],[25],[9],[20],[28],} \\
{[17],[22],[33],[32],[18],[23],[14],} \\
{[42],[26]}\end{array}$ \\
\hline Barriers & $\begin{array}{l}{[15],[1],[12],[10],[13],[19],[5],[35],} \\
{[29],[31],[34],[27],[16],[30],[21],[11],} \\
{[20],[28],[17],[22],[33],[32],[18]}\end{array}$ \\
\hline Benefits & $\begin{array}{l}{[1],[7],[8],[9],[10],[11],[12],[13],} \\
{[21],[14],[33]}\end{array}$ \\
\hline Drivers & $\begin{array}{l}{[17],[21],[24],[20],[25],[29],[30],[31],} \\
{[34]}\end{array}$ \\
\hline Enablers & $\begin{array}{l}\text { [4], [11], [12], [16], [22], [23], [20], [26], } \\
{[33]}\end{array}$ \\
\hline Myths & {$[33],[1]$} \\
\hline
\end{tabular}

All studies mentioned some type of OGD benefit, as they represent the main objectives and motivations of OGD initiatives [7]. However, only $5 \%$ of the studies ([7], [8]) focused exclusively on benefits. Zuiderwijk and associates [7] compared the main objectives of 156 Open Government Data initiatives to one or more benefits delivered and concluded that intended and delivered benefits often differ. In contrast, Jamieson and colleagues [8] challenged three perceived benefits of the production, consumption, and publication of open government data. Authors argued that it is impossible to have a more transparent and efficient public service, a more informed citizen, and to promote innovation, as the newer rhetoric from OGD has moved from how to get and use OGD to the need to address the ethical uses, consumption, storage, and application of data in general.

Factors that hinder or block the use of open data are considered impediments or barriers [45]. OGD use barriers literature is rich and diverse, being discussed in $61 \%$ of the papers, as seen in Table 2. Zuiderwijk and colleagues [42] developed one of the first mappings of Open Government Data socio-technical barriers or impediments users may encounter when using these data.

Open data involves using new technology and can be considered an innovation in the public sector [46]. As such, a set of enabling factors should be in place so that data can be used [12]. Enablers are factors that facilitate or enable the use of open data. They were examined in $16 \%$ of the studies. Although necessary, enablers alone are not enough for public sector innovation. Drivers are factors that push or propel public institutions and their agents towards the use of OGD [46]. Examples of drivers and motivations were provided in $29 \%$ of the papers.
It is worth noting that some enablers may ease or overcome barriers. However, others may not be related to any specific barrier. Studies about the promotion and dissemination of OGD use are included in the enablers stream. Hellberg and Hedström [43] analyzed the challenges of organizing an innovation competition for promoting OGD reuse in a Swedish municipality. At the same time, Matheus and colleagues [44] investigated the effectiveness of strategies such as hackathons, prizes and contests, external partnerships, and data journalism adopted by the Rio de Janeiro municipality to promote the dissemination and expansion of the use of open data.

Janssen and colleagues [1] formalized myths to bridge the gap between open data potential benefits and barriers. A myth is a traditional story or legend widely held but not determined by fact or evidence. An example of such a myth presumes that OGD users have the resources, expertise, and capabilities to use these data. In the same stream, Melin [33] investigated the myths, challenges, and benefits of developing an OGD platform at a Swedish local government. Although fascinating, myths will not be further explored in this review.

\subsection{Benefits of Open Government Data use}

Benefits can be seen as general (achieved by the private or third sectors) or specific to the public sector. Table 3 presents the benefits distilled from the literature. Political and social benefits are considered the most important category [1], [17], as increased transparency, civic participation, and engagement are associated with the main motivations of OGD initiatives [6]. The gain of new knowledge and insights into the public sector is a specific benefit, as is the offer of improved public processes, products, and services. General economic and financial benefits are reduced operating costs and increased administrative efficiency. Technical and operational benefits are the most numerous, being the development of improved public policies and new processes, products, and services among the most cited. These findings suggest that the benefits most reported are more practical than previously reported ([9], [1], [7]).

\section{Table 3 - Benefits of OGD use}

\begin{tabular}{|l|l|}
\hline Category & Benefits \\
\hline $\begin{array}{l}\text { Political and } \\
\text { social }\end{array}$ & Increased transparency [9], [7], [8], [1], \\
& {$[10],[11],[12],[13]$} \\
& Increased social control [9], [1], [7] \\
& Increased civic participation and \\
& public engagement [9], [11], [8], [1], \\
& {$[7],[10],[13]$} \\
& More informed citizens [8] \\
& Increased accountability [7], [9], [8], \\
& {$[1]$} \\
\hline
\end{tabular}




\begin{tabular}{|c|c|}
\hline Category & Benefits \\
\hline & $\begin{array}{l}\text { Gained new knowledge and insights } \\
\text { into the public sector [1], [7], [10], } \\
{[13]}\end{array}$ \\
\hline $\begin{array}{l}\text { Economic and } \\
\text { financial }\end{array}$ & $\begin{array}{l}\text { Increased administrative efficiency [7], } \\
{[8]} \\
\text { Reduced operating costs [7], [21] } \\
\text { Gained access to external capacity and } \\
\text { resources for solving problems [7] } \\
\text { Offer of improved processes, products, } \\
\text { and services [1], [7], [13] }\end{array}$ \\
\hline $\begin{array}{l}\text { Operational } \\
\text { and } \\
\text { technical }\end{array}$ & $\begin{array}{l}\text { Development of improved public } \\
\text { policies [1], [7], [13], [8], [14], [10] } \\
\text { Increased intra-governmental } \\
\text { collaboration [11], [1] } \\
\text { New processes, products, and services } \\
\text { developed [1], [10], [13], [11] } \\
\text { Improved processes [1], [7], [10], [12], } \\
{[11],[33]} \\
\text { Improved data management [1], [7], } \\
{[13],[10]} \\
\text { Improved access to public services } \\
\text { [14], [21] } \\
\text { Increased efficiency in making changes } \\
\text { in service delivery [1], [8], [14], [9] } \\
\text { Decision-making process } \\
\text { informed [1], [7], [13] } \\
\text { Innovation support processes deployed } \\
\text { [1], [7], [11], [8] problem-solving capacity } \\
\text { Increased } \\
\text { [1], [21] } \\
\text { Use of collective intelligence to solve } \\
\text { public problems [1], [7], [13], [11] }\end{array}$ \\
\hline
\end{tabular}

\subsection{Barriers to Open Government Data use}

Table 4 lists OGD use barriers extracted from the literature. Barriers do not exist in a vacuum, they are interrelated and change over time [6], [3], [36], [41], [42]. For example, operational and technical barriers were the most reported. Technical issues related to poor data availability, accessibility, quality, and usability seem to be common problems. They could be imputed to poor data publishing and the absence of data management practices. Moreover, organizational and institutional barriers related to the lack of human resources and organizational capabilities to use open data seem to hinder the organization's capabilities to publish open data.

Another interesting example is policy and legal barriers associated with the lack of or inadequacy of open data policies, laws, standards, and regulations. The publication of data with inappropriate use license and technical issues like poor quality and absent or insufficient metadata may be consequences of these barriers. The organizational and institutional barriers indicate that public entities have no interest in using open data. Disinterest may be caused by an unfavorable organizational culture towards open data, which is the most cited cultural barrier. In addition to the lack of human resources with the knowledge, skills, and/or capabilities to use open data and the high cost to hire people that can use open data (top economic and financial barrier).

\section{Table 4 - Barriers to OGD use}

\begin{tabular}{|c|c|}
\hline Category & Barriers \\
\hline $\begin{array}{l}\text { Policy and } \\
\text { legal }\end{array}$ & $\begin{array}{l}\text { Open data is not a political priority } \\
\text { [20] } \\
\text { Strategy and/or leadership do not } \\
\text { support open data use [23], [19], [21] } \\
\text { Open data policy is inadequate or } \\
\text { lacking [19], [24], [23], [32] } \\
\text { Open data use laws are inadequate or } \\
\text { lacking [10], [12], [36], [32] } \\
\text { Open data use standards and } \\
\text { guidelines are inadequate or lacking } \\
\text { [32], [18] } \\
\text { Use license does not exist, or unclear, } \\
\text { or restrict use [1], [18], [19], [13], } \\
\text { [27], [36] }\end{array}$ \\
\hline Cultural & $\begin{array}{l}\text { Lack of organizational culture } \\
\text { favorable to open data [1], [10], [19], } \\
{[20],[16],[17],[5],[18]} \\
\text { Management and public managers do } \\
\text { not know what open data is [21], [32] }\end{array}$ \\
\hline $\begin{array}{l}\text { Economic and } \\
\text { financial }\end{array}$ & $\begin{array}{l}\text { There is no budget, no financial } \\
\text { resources to use open data [1], [19], } \\
{[36],[32]} \\
\text { Cost to hire people able to use open } \\
\text { data is very high [19], [20], [13], [21], } \\
{[16],[5]}\end{array}$ \\
\hline $\begin{array}{l}\text { Organizational } \\
\text { and } \\
\text { institutional }\end{array}$ & $\begin{array}{l}\text { Upper management does not support } \\
\text { open data use [21], [36] } \\
\text { The organizational structure does not } \\
\text { support open data use [19], [11], [20], } \\
\text { [24], [32] } \\
\text { The organization is not interested in } \\
\text { using open data [1], [19], [11], [25], } \\
\text { [24], [28], [23] } \\
\text { The organization does not have the } \\
\text { organizational capabilities, routines, } \\
\text { and processes to use open data [1], } \\
\text { [19], [13], [36] } \\
\text { Low engagement of public managers } \\
\text { with the use of open data [11], [20], } \\
\text { [36] } \\
\text { Lack of non-financial resources (time, } \\
\text { equipment, etc.) to use open data [1], } \\
\text { [19], [13] } \\
\text { There is no definition of competencies } \\
\text { for the use of open data [32] }\end{array}$ \\
\hline
\end{tabular}




\begin{tabular}{|c|c|}
\hline Category & Barriers \\
\hline & $\begin{array}{l}\text { There are no human resources with the } \\
\text { knowledge, skills and/or capabilities } \\
\text { to use open data [1], [19], [21], [24], } \\
{[22],[23],[36],[32],[18]} \\
\text { Data provider ignores my requests and } \\
\text { suggestions [1], [19], [42], [13], [31], } \\
{[22],[23]}\end{array}$ \\
\hline $\begin{array}{l}\text { Operational } \\
\text { and technical }\end{array}$ & $\begin{array}{l}\text { There is no centralized portal or open } \\
\text { data infrastructure [11], [22] } \\
\text { Difficulty in discovering/locating data } \\
\text { [1], [3], [22] } \\
\text { Data availability issues [1], [28], [5], } \\
\text { [19], [29], [36] } \\
\text { Data accessibility issues [1], [19], [5], } \\
\text { [47], [35], [22], [23], [18] (incomplete, } \\
\text { Poor data quality and/or } \\
\text { inaccurate, obsolete, [1 } \\
\text { inconsistent) [1], [3], [11], [12], [16], } \\
\text { [25], [47], [28], [5], [29], [24], [35], } \\
\text { [31], [22], [23], [36], [32], [18] } \\
\text { Low data usability (fragmented data, } \\
\text { no user-friendly format, not machine } \\
\text { readable) [13], [21], [24], [1], [5], } \\
\text { [24], [3], [22], [32] } \\
\text { Metadata insufficient and/or lacking } \\
\text { [1], [3], [19], [10], [16], [28], [29], } \\
\text { [36], [32], [18] } \\
\text { Data are not compatible and cannot be } \\
\text { compared [3], [1], [13], [28], [36] } \\
\text { Data cannot be combined and } \\
\text { connected [28] } \\
\text { Data are not sustained or maintained } \\
\text { [24], [18] } \\
\text { Data sources are unreliable [1] } \\
\text { Results obtained from different } \\
\text { sources differ [1] } \\
\text { Uploading data is not supported [13] } \\
\text { No processing power [5], [13] } \\
\text { Lack of proper tools to manipulate } \\
\text { data [32], [18] inter } \\
\text { Difficulties to interact with the data } \\
\text { provider [35], [24] }\end{array}$ \\
\hline
\end{tabular}

\subsection{Enablers of Open Government Data use}

Table 5 shows factors that enable or facilitate OGD use distilled from the literature. The most cited internal enabler is that the Administration promotes and internally discloses the use of open data. Examples of external enablers are the existence of public/private partnerships supporting open data, and there is external pressure from international bodies to use open data. They are all specific to the public sector. Most policy and legal enablers overcome or ease corresponding barriers. Operational and technical enablers like the existence of an open data portal and infrastructure and the availability of high-quality data also overcome specific barriers. Publicizing and offering case studies that facilitate OGD use does not correspond to any reported barrier.

\section{Table 5 - Enablers of OGD use}

\begin{tabular}{|c|c|}
\hline Category & Enablers \\
\hline $\begin{array}{l}\text { Political and } \\
\text { social }\end{array}$ & $\begin{array}{l}\text { Political leadership is committed to } \\
\text { open data use [4], [22] } \\
\text { Management and public managers are } \\
\text { aware of open data [16] } \\
\text { External stakeholders (international } \\
\text { bodies, journalists) disseminate and } \\
\text { promote the use of open data [11], [22] }\end{array}$ \\
\hline $\begin{array}{l}\text { Policy and } \\
\text { legal }\end{array}$ & $\begin{array}{l}\text { There is legal compliance pressure [4], } \\
\text { [11] } \\
\text { Public open data policy exists [12], [4], } \\
\text { [22], [23] } \\
\text { Laws governing the use of open data } \\
\text { exist [4], [11], [20] } \\
\text { Regulations and open data standards } \\
\text { exist [16], [4] }\end{array}$ \\
\hline Cultural & $\begin{array}{l}\text { Organizational culture facilitates the } \\
\text { use of open data [4], [20] }\end{array}$ \\
\hline $\begin{array}{l}\text { Economic and } \\
\text { financial }\end{array}$ & $\begin{array}{l}\text { Financial resources are available to } \\
\text { support the use of open data [4] }\end{array}$ \\
\hline $\begin{array}{l}\text { Organizational } \\
\text { and } \\
\text { institutional }\end{array}$ & $\begin{array}{l}\text { The Administration promotes and } \\
\text { internally discloses the use of open data } \\
\text { [11], [23], [33] } \\
\text { There have been changes in the } \\
\text { organizational structure to support } \\
\text { open data [16], [26] } \\
\text { The organization } \\
\text { digitization/digitalization capacity [4] } \\
\text { Managers are motivated to use open } \\
\text { data [4] } \\
\text { There is external pressure (from } \\
\text { international bodies, other bodies) to } \\
\text { use open data [11], [33] }\end{array}$ \\
\hline $\begin{array}{l}\text { Operational } \\
\text { and technical }\end{array}$ & $\begin{array}{l}\text { There are open data portals and } \\
\text { infrastructure [11], [22] } \\
\text { Case studies and examples are } \\
\text { available on the Open Data Portal [16] } \\
\text { High-quality data is available [11], [4], } \\
\text { [22], [26] } \\
\text { Data are improved [12] } \\
\text { Tools and mechanisms to work with } \\
\text { open data are available [26] } \\
\text { There are public/private partnerships } \\
\text { supporting the use of open data [23], } \\
\text { [26] }\end{array}$ \\
\hline
\end{tabular}

\subsection{Drivers of Open Government Data use}

Table 6 presents Open Government Data (OGD) use drivers found in the literature. It is worth noting that this list was abridged to remove redundancy with 
enablers. Depending on the context, the same factor is referenced in the literature as a driver or enabler. See, for example, policy and legal enablers in Table 5 and corresponding drivers in Table 6. The most significant driver identified was the institutionalization of open data use practices in the Administration. It is followed by policy and legal drivers related to the existence of open data policies, laws, and standards and a cultural driver associated with the institutional culture supporting open data use. Institutionalization is the process of routinizing cultural practices, rules, and norms [24]. Thus, findings seem reasonable, as public administration practices are bound by laws and public agents tend to use established institutional and cultural practices.

\section{Table 6 - Drivers of OGD use}

\begin{tabular}{|l|l|}
\hline Category & Drivers \\
\hline $\begin{array}{l}\text { Social and } \\
\text { political }\end{array}$ & $\begin{array}{l}\text { Pressure from external stakeholders to } \\
\text { use open data [21] } \\
\text { Raise OGD use awareness [34] }\end{array}$ \\
\hline $\begin{array}{l}\text { Policy and } \\
\text { legal }\end{array}$ & $\begin{array}{l}\text { Existence of public policies of open } \\
\text { data [24], [20] } \\
\text { Existence of laws governing the use of } \\
\text { open data [25], [21] } \\
\text { Existence of regulations, standards, } \\
\text { and standards for using open data [24] }\end{array}$ \\
\hline $\begin{array}{l}\text { Economic and } \\
\text { financial }\end{array}$ & $\begin{array}{l}\text { Existence financial resources have a } \\
\text { significant positive influence on open } \\
\text { data success [17] }\end{array}$ \\
\hline $\begin{array}{l}\text { Organizational } \\
\text { and } \\
\text { institutional }\end{array}$ & $\begin{array}{l}\text { Open data use is institutionalized in the } \\
\text { Administration [30], [24], [17] }\end{array}$ \\
\hline $\begin{array}{l}\text { Operational } \\
\text { and } \\
\text { technical }\end{array}$ & $\begin{array}{l}\text { Provision of proper } \\
\text { infrastructure [24] } \\
\text { Data available in user-friendly formats } \\
\text { [31] } \\
\text { Data search facilities available [31] } \\
\text { Existence of historical data [29] } \\
\text { Existence of metadata [31] } \\
\text { Possible to share data via social media } \\
\text { [31] } \\
\text { Provision of data suggested by users } \\
\text { [29] }\end{array}$ \\
\hline
\end{tabular}

The following section briefly summarizes findings specific to the public sector. It presents our conclusions and suggestions for future research.

\section{Conclusions and future research}

Answering our research questions, we recap the most relevant findings specific to Open Government Data (OGD) use by the public sector.

RQ1 - What are the benefits promoted by OGD use? Reported benefits specific to the public sector were gained new knowledge and insights into the public sector, the offer of improved processes, products, and services, and the development of improved public policies. In addition to the usual social and political benefits, the significant number of operational and technical benefits indicate growing data use.

RQ2 - What are the factors that hinder (barriers) OGD use? Unfavorable organizational culture towards open data and the high costs to hire skilled data professionals hinders OGD use. Additionally, technical and operational barriers related to poor data availability, quality, and usability were the most reported. At the same time, prominent institutional and organizational barriers are the lack of organizational capabilities, routines, and processes to use open data and the lack of human resources with knowledge, skills, and/or capabilities to use open data. Policy and legal barriers are associated with the absence and inadequacy of public open data policies, laws, and standards.

RQ3 - What are the factors that facilitate or enable (enablers) OGD use? Organizational and institutional enablers specific to the public sector are related to the Administration promoting and internally disclosing the use of open data. In addition to making structural, organizational changes to support data use. External factors like the pressure from international bodies to use open data and open data dissemination by journalists enable OGD use in public administrations.

RQ4 - What are the factors that propel (drivers) OGD use? The topmost drivers are establishing public open data policies, laws, and regulations and institutionalizing open data in public administrations.

As most prominent OGD use barriers are of technical and organizational nature, we conclude that open data use in the public sector is still in its infancy. Thus, the institutionalization of open data in public administrations may offer a viable path to use these data effectively.

A limitation of this work is the scope of the databases searched. Thus, the inclusion of a specialized the Digital Government Reference Library (DGRL) database could broaden this research and strength analysis [40].

Previous research [45] found that barriers identified in the literature differ from those found in empirical research and that they change over time [36], [41]. Thus, to further this research and obtain comprehensive lists of benefits, barriers, drivers, and enablers, an empirical study is required. Our overview can be used as a base to improve Open Government Data use processes and be extended in future studies.

\section{References}

[1] M. Janssen, Y. Charalabidis, and A. Zuiderwijk, "Benefits, adoption barriers and myths of open data 
and open government," Information systems management, vol. 29, no. 4, pp. 258-268, 2012.

[2] M. Gascó-Hernández, E. G. Martin, L. Reggi, S. Pyo, and L. F. Luna-Reyes, "Promoting the use of open government data: Cases of training and engagement," Government Information Quarterly, vol. 35, no. 2, pp. 233-242, Apr. 2018, doi: 10.1016/j.giq.2018.01.003.

[3] J. Crusoe and U. Melin, "Investigating open government data barriers: A literature review and conceptualization," Lecture Notes in Computer Science (including subseries Lecture Notes in Artificial Intelligence and Lecture Notes in Bioinformatics), vol. 11020 LNCS, pp. 169-183, 2018, doi: 10.1007/978-3-319-98690-6 15.

[4] M. M. Khurshid et al., "Modeling of Open Government Data for Public Sector Organizations Using the Potential Theories and Determinants-A Systematic Review," Informatics, vol. 7, no. 3, p. 24, 2020, doi: http://dx.doi.org/10.3390/informatics7030024.

[5] J. Wieczorkowski, "Barriers to Using Open Government Data," in Proceedings of the 2019 3rd International Conference on E-commerce, E-Business and E-Government - ICEEG 2019, Lyon, France, 2019, pp. 15-20. doi: 10.1145/3340017.3340022.

[6] J. Attard, F. Orlandi, S. Scerri, and S. Auer, "A systematic review of open government data initiatives," Government Information Quarterly, vol. 32, no. 4, pp. 399-418, Oct. 2015, doi: 10.1016/j.giq.2015.07.006.

[7] A. Zuiderwijk, R. Shinde, and M. Janssen, "Investigating the attainment of open government data objectives: is there a mismatch between objectives and results?," International Review of Administrative Sciences, vol. 85, no. 4, pp. 645-672, Dec. 2019, doi: $10.1177 / 0020852317739115$.

[8] D. Jamieson, R. Wilson, and M. Martin, "The (im)possibilities of open data?," Public Money \& Management, vol. 39, no. 5, pp. 364-368, Jul. 2019, doi: $10.1080 / 09540962.2019 .1611240$.

[9] C. S. Albano, M. H. de Araujo, and N. Reinhard, "Motivators and facilitators of relationships in networks: how public managers acknowledge these factors in open government data," Navus - Revista de Gestão e Tecnologia, vol. 7, no. 1, pp. 73-92, Jan. 2017, doi: 10.22279/navus.2017.v7n1.p73-92.462.

[10] C. S. Albano and G. da S. Craveiro, "Lessons Learned from the Use of Budgetary Data Open Format: an Exploratory Study in the Brazilian Ecosystem," Revista de Gestão e Projetos, vol. 06, no. 03, pp. 1727, Dec. 2015, doi: 10.5585/gep.v6i3.370.

[11] C. Albano and N. Reinhard, "Open Government Data: facilitating and motivating factors for coping with potential barriers in the Brazilian context," in Electronic Government. EGOV 2014. Lecture Notes in Computer Science, Sep. 2014, p. 193. doi: 10.1007/978-3-662-44426-9 15.

[12] C. S. Albano and N. Reinhard, "Challenges for governments and society in the Brazilian Ecosystem of Open Government Data," CADERNOS GESTAO
PUBLICA E CIDADANIA, vol. 20, no. 67, pp. 214 234, Dec. 2015, doi: 10.12660/cgpc.v20n67.41150.

[13] G. S. Craveiro and C. S. Albano, "Budgetary Data (in an Open Format) Benefits, Advantages, Obstacles and Inhibitory Factors in the View of the Intermediaries of this System: A Study in Latin American Countries," in Open and Big Data Management and Innovation, Cham, 2015, pp. 223-235. doi: 10.1007/978-3-31925013-7_18.

[14] E. Parkes, T. Karger-Lerchl, P. Wells, J. Hardinges, and R. Vasileva, "Using open data to deliver public services,” Open Data Institue, Feb. 2018. [Online]. Available: https://theodi.org/article/using-open-datafor-public-services-report-2/

[15] C. Martin, "Barriers to the Open Government Data Agenda: Taking a Multi-Level Perspective," Policy \& Internet, vol. 6, no. 3, pp. 217-240, 2014, doi: 10.1002/1944-2866.POI367.

[16] E. Shepherd et al., "Open government data: critical information management perspectives," Records Management Journal, vol. 29, no. 1/2, pp. 152-167, Mar. 2019, doi: 10.1108/RMJ-08-2018-0023.

[17] Kim and Eom, "The Managerial Dimension of Open Data Success: Focusing on the Open Data Initiatives in Korean Local Governments," Sustainability, vol. 11, no. 23, p. 6758 , Nov. 2019, doi: $10.3390 /$ sul1236758.

[18] G. Smith and J. Sandberg, "Barriers to innovating with open government data: Exploring experiences across service phases and user types," Information Polity, vol. 23, no. 3, pp. 249-265, Aug. 2018, doi: 10.3233/IP-170045.

[19] J. Kučera, "Analysis of barriers to publishing and reuse of Open Government Data," Digitalization in Management, Society and Economy. 25th Interdisciplinary Information Management Talks IDIMT-2017, p. 11, 2017.

[20] T. Cahlikova and V. Mabillard, "Open Data and Transparency: Opportunities and Challenges in the Swiss Context," Public Performance \& Management Review, vol. 43, no. 3, pp. 662-686, May 2020, doi: 10.1080/15309576.2019.1657914.

[21] K. M. Chorley, "The challenges presented to records management by open government data in the public sector in England: A case study," Records Management Journal, vol. 27, no. 2, pp. 149-158, Jul. 2017, doi: 10.1108/RMJ-09-2016-0034.

[22] L. F. Luna-Reyes, "US open data policy: advances and recommendations," in Proceedings of the 19th Annual International Conference on Digital Government Research: Governance in the Data Age, Delft The Netherlands, May 2018, pp. 1-10. doi: 10.1145/3209281.3209308.

[23] R. Ma and P. T. I. Lam, "Investigating the barriers faced by stakeholders in open data development: A study on Hong Kong as a 'smart city,"' Cities, vol. 92, pp. 36-46, Sep. 2019, doi: 10.1016/j.cities.2019.03.009.

[24] R. Huang, T. Lai, and L. Zhou, "Proposing a framework of barriers to opening government data in China: A critical literature review," Library Hi Tech, 
vol. 35 , no. 3 , pp. $421-438$, Sep. 2017 , doi: 10.1108/LHT-01-2017-0014.

[25] J. Y. Cho and B. G. Lee, "Creating value using public big data: comparison of driving factors from the provider's perspective," Information Technology \& People, vol. ahead-of-print, no. ahead-of-print, Jan. 2020, doi: 10.1108/ITP-04-2019-0169.

[26] I. Susha, Å. Grönlund, and M. Janssen, "Organizational measures to stimulate user engagement with open data," Transforming Government: People, Process and Policy, vol. 9, no. 2, pp. 181-206, May 2015, doi: 10.1108/TG-05-20140016.

[27] M. Mockus, "OGDL4M Ontology: Analysis of EU Member States National PSI Law," in Research and Practical Issues of Enterprise Information Systems, vol. 268, A. M. Tjoa, L. D. Xu, M. Raffai, and N. M. Novak, Eds. Cham: Springer International Publishing, 2016, pp. 59-73. doi: 10.1007/978-3-319-49944-4 5.

[28] J. Crusoe, A. Simonofski, A. Clarinval, and E. Gebka, "The Impact of Impediments on Open Government Data Use: Insights from Users," in 2019 13th International Conference on Research Challenges in Information Science (RCIS), May 2019, pp. 1-12. doi: 10.1109/RCIS.2019.8877055.

[29] S. Saxena, “'Usage by stakeholders' as the objective of 'transparency-by-design' in open government data: Case study of Sri Lanka's open data initiative," Information and Learning Science, vol. 118, no. 7/8, pp. 420-432, Jul. 2017, doi: 10.1108/ILS-05-20170034.

[30] S. Saxena, "Drivers and barriers towards re-using open government data (OGD): a case study of open data initiative in Oman," foresight, vol. 20, no. 2, pp. 206-218, Jan. 2018, doi: 10.1108/FS-10-2017-0060.

[31] S. Saxena, "Drivers and barriers to re-use Open Government Data (OGD): a case study of open data initiative in Philippines," Digital Policy, Regulation and Governance, vol. 20, no. 4, pp. 358-368, Jun. 2018, doi: 10.1108/DPRG-08-2017-0045.

[32] D. D. Shao and S. Saxena, "Barriers to Open Government Data (OGD) initiative in Tanzania: Stakeholders' perspectives," Growth and Change, vol. 50, no. 1, pp. 470-485, 2019, doi: https://doi.org/10.1111/grow.12282.

[33] U. Melin, "Challenges and Benefits in an Open Data Initiative - A Local Government Case Study of Myths and Realities," in 2016 Electronic Government And Electronic Participation, 2016, p. 12. doi: 10.3233/978-1-61499-670-5-111.

[34] J. Cranefield, O. Robertson, and G. Oliver, "Value in the mash: Exploring the benefits, barriers and enablers of open data apps," Tel Aviv, 2014, p. 15.

[35] E. H. Gebre and E. Morales, "How 'accessible' is open data? Analysis of context-related information and users' comments in open datasets," Information and Learning Sciences, vol. 121, no. 1/2, pp. 19-36, Jan. 2020, doi: 10.1108/ILS-08-2019-0086.

[36] H. N. Roa, E. Loza-Aguirre, and P. Flores, "A Survey on the Problems Affecting the Development of Open
Government Data Initiatives," in 2019 Sixth International Conference on eDemocracy \& eGovernment (ICEDEG), Quito, Ecuador, Apr. 2019, pp. 157-163. doi: 10.1109/ICEDEG.2019.8734452.

[37] J. Webster and R. T. Watson, "Analyzing the Past to Prepare for the Future: Writing a literature Review," p. 11, 2002.

[38] B. Kitchenham, "Procedures for Undertaking Systematic Reviews, Joint Technical Report," Computer Science Department, Keele University (TR/SE- 0401) and National ICT Australia Ltd. ( 0400011T.1), Joint Technical Report TR/SE-0401 / 0400011T.1, Jul. 2004.

[39] H.-F. Hsieh and S. E. Shannon, "Three Approaches to Qualitative Content Analysis," Qualitative Health Research, vol. 15, no. 9, pp. 1277-1288, Nov. 2005, doi: $10.1177 / 1049732305276687$.

[40] P. Mongeon and A. Paul-Hus, "The journal coverage of Web of Science and Scopus: a comparative analysis," Scientometrics, vol. 106, no. 1, 2016, doi: 10.1007/s11192-015-1765-5.

[41] A. Zuiderwijk and M. Janssen, "Barriers and development directions for the publication and usage of open data: A socio-technical view," Public Administration and Information Technology, vol. 4, pp. 115-135, 2014, doi: 10.1007/978-1-4614-95635_8.

[42] A. Zuiderwijk, M. Janssen, and S. Choenni, "Open Data Policies: Impediments and Challenges," in Proceedings of the 12th European Conference on EGovernment, Vols 1 and 2, 2012, pp. 794-801.

[43] A.-S. Hellberg and K. Hedström, "The story of the sixth myth of open data and open government," Transforming Government: People, Process and Policy, vol. 9, no. 1, pp. 35-51, Mar. 2015, doi: 10.1108/TG-04-2014-0013.

[44] R. Matheus, M. Maia Ribeiro, and J. C. Vaz, "Strategies and instruments for the dissemination and promotion of open government data use in Brazil: case study of Rio de Janeiro city hall," Revista Tecnologia e Sociedade, vol. 14, no. 33, Jul. 2018, doi: $10.3895 /$ rts.v14n33.6866.

[45] A. Zuiderwijk, M. Janssen, S. Choenni, R. Meijer, and R. S. Alibaks, "Socio-technical Impediments of Open Data," Electronic Journal of e-Government, p. 18, 2012.

[46] P. Ulrich and A. Perego, "Emerging and Disruptive Technologies for Public Service Innovation: A scoping report for Europe," European Commission, Technical, 2020.

[47] A. Eberhardt and M. S. Silveira, "Show me the data!: a systematic mapping on open government data visualization," in Proceedings of the 19th Annual International Conference on Digital Government Research: Governance in the Data Age, Delft The Netherlands, May 2018, pp. 1-10. doi: $10.1145 / 3209281.3209337$. 